\title{
CARACTERIZAÇÃO DO TOMATEIRO SUBMETIDO AO DÉFICIT HÍDRICO
}

\section{CHARACTERIZATION OF TOMATO PLANTS SUBJECTED TO WATER DEFICIT}

\author{
Rafael Gustavo Ferreira MORALES ${ }^{1}$ \\ Luciane Vilela RESENDE ${ }^{2}$ \\ Isadora Carlos BORDINI ${ }^{3}$ \\ Alexandre Gonçalves GALVÃO 4 \\ Fátima Conceição REZENDE ${ }^{5}$
}

\section{RESUMO}

O experimento foi conduzido com o objetivo avaliar as características morfofisiológicas do tomateiro quando submetido a diferentes níveis de déficit hídrico e, com base nesses resultados, indicar os melhores caracteres para seleção de plantas com maior resistência ao déficit hídrico. O delineamento experimental foi em blocos casualizados, com quatro repetições, no esquema de parcelas subdivididas, em que os tratamentos principais (parcelas) foram constituídos por duas linhagens (TOM-684 e M-82) e as subparcelas por quatro níveis de umidade do solo $(100 \%, 75 \%, 50 \%$ e $25 \%$ da capacidade de campo). Foram avaliados os seguintes caracteres: produção de frutos, massa fresca e seca das folhas, caule e sistema radicular, diâmetro do caule, altura das plantas, número de folhas, fotossíntese, transpiração, temperatura foliar, umidade intercelular, dióxido de carbono intercelular, condutância estomática, condutância de $\mathrm{CO}_{2}$ intercelular e condutância total. Com a redução da umidade do solo houve redução do número de folhas, altura das plantas, massa fresca e seca das folhas, caule e sistema radicular, transpiração, taxa fotossintética, produção de frutos e aumento da temperatura foliar. A condutância estomática diferiu entre as duas linhagens, com maiores valores para a cultivar TOM-684, que reduziu a condutância estomática de 0,70 para $0,25 \mathrm{~mol} \mathrm{~m}^{-2} \mathrm{~s}^{-1}$ entre os níveis de 100 e $25 \%$ da capacidade de campo. A altura das plantas e o número de folhas podem ser utilizadas em programas de melhoramento como ferramenta para seleção de plantas com maior resistência ao déficit hídrico.

Palavras-chave: Solanum lycopersicum; Tolerância a seca; Déficit hídrico; Eficiência do uso da água.

\section{ABSTRACT}

The experiment was conducted to evaluate the morphological/physiological characteristics of tomato plants when submitted to different levels of water deficit and, based on these results, indicate the best characters for the selection of plants with more tolerance to water deficit. The experimental delineation was in randomized complete block design, with four replications, arranged in splitplot, in which the main treatments (plots) were composed by two strains (TOM-684 and M-82) and the subplots, by four levels of soil moisture $(100 \%, 75 \%, 50 \%$ and $25 \%$ of the field capacity). The following parameters were evaluated: fruit production, leaf, stem and root system fresh and dry mass, , stem diameter, plant height, number of leaves, photosynthesis, transpiration, foliar temperature, intracellular moisture, intracellular carbon dioxide, stomatal conductance, conductance of intracellular $\mathrm{CO}_{2}$ and total conductance. With the reduction of soil moisture occurred reduction in the number of leaves, plant height and leaf, stem and root system fresh and dry mass, transpiration, photosynthetic rate, fruit production and increase of foliar temperature The stomatal conductance differed between both strains, with higher values for the TOM-684 strain, which reduced stomatal conductance from 0,70 to $0,25 \mathrm{~mol} \mathrm{~m}^{-2} \mathrm{~s}^{-1}$ between levels of 100 and $25 \%$ of field capacity. Plant height and the number of leaves may be used in breeding programs as a tool for the selection of plants with higher resistance to water deficit.

Key-words: Solanum lycopersicum; Drought tolerance; Water deficit; Water use efficiency.

\footnotetext{
${ }^{1}$ Doutor, Pesquisador, Empresa de Pesquisa Agropecuária e Extensão Rural de santa Catarina (EPAGRI), Estação Experimental de Itajaí, Rod. Antônio Heil, 6800, Itajaí, SC. E-mail: rafaelmorales@epagri.sc.gov.br

${ }^{2}$ Doutorado em Agronomia pela Universidade Federal de Lavras, email: luciane.vilela@dag.ufla.br

${ }^{3}$ Graduanda em Agronomia pela Universidade Federal de Lavras, email: isabordini@hotmail.com

${ }^{4}$ Doutorando em Agronomia pela Universidade Federal de Lavras, email: galvao.alexandre@hotmail.com

${ }^{5}$ Doutorado em Irrigação e Drenagem, Departamento de Engenharia agrícola da Universidade Federal de Lavras, MG, Brasil. email: frezende@deg.ufla.br
} 
MORALES, R.G.F. et al. Caracterização de tomateiro...

\section{INTRODUÇÃO}

A resposta das plantas ao déficit hídrico está relacionada a uma rede complexa de mudanças morfológicas e fisiológicas. As alterações morfológicas podem ser de simples aferição, como redução do tamanho da planta e da folha, abscisão foliar e redução da produtividade; mas podem ser também mais complexas, como o aumento do volume do sistema radicular e redução da massa fresca e seca das diferentes partes da planta (parte aérea, frutos e caule) (Torrecillas et al., 1996). Essas alterações ocorrem, indiretamente, devido a uma série de mudanças fisiológicas, como redução do conteúdo de água na folha (Hetherington \& Woodward, 2003), fechamento dos estômatos (ROYER, 2001), deposição de cera na cutícula (Kerstiens, 2006), redução da fotossíntese (Srinivasa Rao et al., 2001) e produção de solutos orgânicos que protegem as plantas de estresses por meio de diferentes rotas metabólicas (Bohnert \& Jensen, 1996).

As diferentes respostas das plantas podem ser determinadas por medidas fisiológicas capazes de identificar a condição hídrica que as mesmas apresentam. Dentre esses indicadores, pode-se citar a temperatura foliar (Kirkham, 2005), o conteúdo relativo de água na folha (Katerji et al., 1988; Lafitte, 2002), a condutância estomática (Kochler et al., 2007), o potencial da água na folha e no solo (Katerji et al., 1988; Bergonci et al., 2000), dentre outros.

Compreender a resposta das plantas ao déficit hídrico é o primeiro passo adotado nos programas de melhoramento de diversas culturas. Para o trevo branco, foram avaliadas diversas características que poderiam estar associadas ao déficit hídrico, sendo a taxa fotossintética e o número de folhas vivas os caracteres mais indicados para a seleção de plantas resistentes ao déficit hídrico (Bortolini et al., 2011). Na cultura do arroz, a resistência à seca está relacionada a diversos caracteres morfológicos, como sistema radicular mais vigoroso, deposição de cera nas folhas, enrolamento foliar e redução da área foliar conforme o estresse é intensificado (Luo, 2010). Para o tomateiro, sabe-se que a restrição hídrica reduz a produtividade, aumenta a incidência de frutos com podridão apical (Sá et al., 2005), reduz a fotossíntese, a condutância estômatica e transpiração das plantas (Srinivasa Rao et al., 2001).

A partir da identificação de indicadores confiáveis e, que apresentem praticidade na utilização, é possível fazer seleção de genótipos resistentes ao déficit hídrico em programas de melhoramento. A identificação de características morfológicas e a compreensão dos mecanismos fisiológicos das plantas submetidas ao déficit hídrico podem auxiliar os melhoristas na seleção de genótipos resistentes ao déficit hídrico. Sendo assim, objetivou-se avaliar as características morfofisiológicas do tomateiro quando submetido a diferentes níveis de déficit hídrico e, com base nesses resultados, indicar os melhores caracteres para seleção de plantas com maior resistência ao déficit hídrico.

\section{MATERIAL E MÉTODOS}

O experimento foi conduzido no Setor de Olericultura do Departamento de Agricultura da Universidade Federal de Lavras (UFLA), localizado no município de Lavras, MG (21013'55" S e $44^{\circ} 57^{\prime} 43^{\prime \prime} \mathrm{W}$, altitude de $925 \mathrm{~m}$ ), entre os meses de junho e novembro de 2010. O clima da região é classificado como mesotérmico, com verões brandos e suaves, com estiagem de inverno (Cwa segundo a classificação de Köppen). Durante o período experimental a temperatura e a umidade relativa do ar no interior do ambiente protegido foram registradas por termohigrômetro digital (modelo HT-210), colocado à altura do dossel das plantas. Os valores médios das máximas e mínimas registrados foram de 38,3 e $22,5{ }^{\circ} \mathrm{C}$ e de 78,6 e $55,3 \%$, respectivamente.

Foram utilizados os seguintes materiais: cultivar M-82, que possui crescimento determinado e foi desenvolvida na Universidade da Califórnia, Davis; TOM-684, que é uma linhagem quase isogênica de TOM-584, que por vez deriva do cruzamento [(Santa Clara x Stevens) x Santa Clara], após seleção para resistência a tospovírus.

A semeadura foi realizada em bandejas de isopor de 128 células, preenchidas com substrato comercial. As mudas foram irrigadas diariamente, até o ponto de transplantio, que foi 30 dias após a semeadura. As plantas foram conduzidas em vasos de $12 \mathrm{~L}$ de capacidade, contendo $50 \%$ de substrato comercial e $50 \%$ de solo de área não cultivada. Nesta mistura foi adicionado $500 \mathrm{~g}$ do formulado NPK 4-14-8 e $500 \mathrm{~g}$ de calcário calcítico para $50 \mathrm{~kg}$ de mistura. Os vasos foram dispostos sobre bancada de concreto, com espaçamento de $30 \mathrm{~cm}$ entre vasos e 1,5 m entre blocos, em ambiente protegido, cuja cobertura era de filme de polietileno transparente de baixa densidade, com espessura de $150 \mu \mathrm{m}$.

O delineamento experimental foi em blocos casualizados com três repetições, no esquema de parcelas subdivididas. Os tratamentos principais (parcelas) foram constituídos por duas linhagens (TOM-684 e M-82) e as subparcelas por quatro níveis de umidade do solo $(100 \%, 75 \%, 50 \%$ e 25 $\%$ da capacidade de campo). Cada subparcela foi composta por seis plantas, sendo que destas, quatro foram utilizadas para a avaliação das características morfofisiológicas, e quatro conduzidas até o final do ciclo para avaliação da produção de frutos.

O controle fitossanitário foi realizado semanalmente, utilizando os seguintes ingredientes ativos (i.a): Acefato (570 g i.a. ha $\left.{ }^{-1}\right)$, Triflumurom (150 g i.a. ha $\left.{ }^{-1}\right)$ e Thiamethoxam (10 g i.a. ha $\left.{ }^{-1}\right)$ no controle de pragas; e Oxicloreto de Cobre (500 g i.a. ha ${ }^{-1}$ ), Metalaxil-M (3 g i.a. ha ${ }^{-1}$ ), Mancozebe (45 g i.a. ha $^{-1}$ ) e Clorotalonil (520 g i.a. ha ${ }^{-1}$ ) no controle de doenças. Juntamente com o controle fitossanitário foi aplicado adubo foliar à base de cálcio, visando à redução da podridão apical dos frutos. 
MORALES, R.G.F. et al. Caracterização de tomateiro...

O manejo da irrigação foi realizado com base na umidade do solo, sendo a mesma monitorada com um medidor eletrônico (hidrofarm), modelo HFM 2010, que faz a leitura pela tecnologia ISAF (impedância do solo em alta frequência). Os vasos foram preenchidos com solo seco em estufa e foi instalado o hidrofarm, obtendo-se o peso seco (PS) de $11,5 \mathrm{~kg}$ e leitura no hidrofarm de $12 \%$ (Lps). Em seguida os mesmos foram saturados e, após o término da percolação foram pesados (PU), obtendose $12,6 \mathrm{~kg}$ e leitura no hidrofarm de $65 \%$ (Lpu). A diferença entre PS e PU foi atribuída à capacidade de armazenamento de água no vaso (Cav). Considerando que $1,0 \mathrm{~g}$ equivale a $1 \mathrm{~mL}$ a capacidade de armazenamento de água nos vasos, a capacidade de armazenamento foi de 1,1 L. Diariamente foram feitas leituras com o hidrofarm em cada tratamento. Os tratamentos de irrigação foram definidos em função da reposição de água (T) sendo: $100 \%, 75$ $\%$, $50 \%$ e $25 \%$. As leituras no Hidrofarm foram realizadas diariamente e até 20 dias após o transplantio todos os tratamentos foram irrigados mantendo a umidade equivalente á capacidade de armazenamento de água nos vasos para garantir o pegamento das mudas. O volume de água aplicado em cada tratamento foi calculado por:

$$
\left.V=\left\{(\text { Lpus - Lps }) \times \frac{T}{100}+\text { Lps }\right]\right\}- \text { LDH } \times Q A
$$

em que:

$\mathrm{V}$ - volume em $\mathrm{mL}$

Lpu - leitura no hidrofarm do vaso saturado com água (65 \%)

Lps - leitura no hidrofarm do vaso com solo $\operatorname{seco}(12 \%)$

$\mathrm{T}$ - níveis de reposição de água $(1,0 ; 0,75$; $0,50$ e 0,25$)$

LDH - leitura diária com o hidrofarm ( \%);

$$
\mathrm{QA}=\left[\frac{\mathrm{Cav}}{\mathrm{Lpu}-\mathrm{Lps}}\right] \times 1000
$$

em que:

Cav $=1,1 \mathrm{~L}$

$\mathrm{QA}=[1,1 /(65-23)]^{\star 1000} \mathrm{QA}=20,75 \mathrm{~mL}$

Aos 75 DAT foram avaliados os seguintes caracteres: fotossíntese, transpiração, temperatura foliar, umidade intercelular, dióxido de carbono intercelular, razão entre o dióxido de carbono intercelular e o ambiental ( $\mathrm{Ci} / \mathrm{Ca})$, condutância estomática, condutância de $\mathrm{CO}_{2}$ intercelular e condutância total. A eficiência no uso da água foi obtida por meio da relação entre fotossíntese e transpiração. Para tanto, foi utilizado o sistema fechado portátil de fotossíntese, IRGA, modelo LI6200 (LI-COR), com fluxo de fótons fotossinteticamente ativos de $930 \pm 120 \mathrm{mmol} \mathrm{m}^{-2} \mathrm{~s}^{-1}$ e com fonte de luz constante de $900 \mu \mathrm{mol}$ de fótons $\mathrm{m}^{-2} \mathrm{~s}^{-1}$. Foram feitas medições nas três plantas de cada parcela, nos três terços das plantas, obtendose uma média por planta e por parcela. Essas medições foram feitas em folhas totalmente expandidas, entre $11 \mathrm{~h}$ e $13 \mathrm{~h}$.
Aos 80 DAT foi avaliada a altura da planta, o número de folhas e o diâmetro do caule. A altura foi mensurada com trena metálica, apenas na cultivar TOM-684 que é de hábito de crescimento indeterminado, tomando-se como referência o meristema apical e a região do colo da planta, sendo o resultado expresso em $\mathrm{cm}$. A altura da cultivar M-82 não foi avaliada devido a mesma possuir hábito de crescimento determinado. Em seguida, as folhas (haste foliar) foram contadas, determinando-se o número de folhas por planta. $\mathrm{O}$ diâmetro do caule foi determinado com o auxílio de um paquímetro digital, com duas casas decimais de precisão, dois $\mathrm{cm}$ acima da região de inserção do caule no solo.

Aos 90 DAT, três plantas foram fragmentadas em folha, caule e raiz. As três partes foram pesadas para a determinação da massa fresca e submetidas à secagem em estufa de circulação forçada de ar, na temperatura de $65^{\circ} \mathrm{C}$, até peso constante, para a determinação da massa seca, em g planta ${ }^{-1}$. A razão raiz/parte aérea foi calculada com base na massa seca da raiz e massa seca do caule mais folhas. As plantas remanescentes foram conduzidas até o final do ciclo produtivo, irrigando-se diariamente os vasos a partir dessa fase, eliminando-se, portanto, as condições de déficit hídrico. Essa medida foi necessária para evitar a morte das plantas dos tratamentos de 50 e $25 \%$ da Cc.

Os frutos foram colhidos a cada três dias, desde o início do ciclo produtivo (45 DAT), finalizando a colheita aos 120 DAT, determinando-se a produção de frutos por planta.

Os dados foram submetidos à análise de variância, aplicando-se análise de regressão para interpretação dos dados. Foram determinados os coeficientes $r$ (Pearson), testados pelo teste $t$ $(p<0,05)$, para estabelecer possíveis correlações entre os fatores analisados. As médias referentes às linhagens foram comparadas pelo teste de Tukey $(p<0,05)$.

\section{RESULTADOS E DISCUSSÃO}

O diâmetro do caule, a razão raiz/parte aérea, a condutância de $\mathrm{CO}_{2}$ intercelular e a condutância total não foram influenciadas pela variação da umidade do solo. Dentre os caracteres morfológicos, a massa seca do sistema radicular foi o único parâmetro em que não houve diferença entre as linhagens. Entre os caracteres fisiológicos, apenas a condutância estomática apresentou diferença entre as linhagens.

Com a redução da umidade do solo e, presumivelmente, aumento do déficit hídrico das plantas, houve redução da massa fresca e seca das folhas, do caule e sistema radicular nas duas linhagens de tomateiro (Figuras 1 e 2). Essa redução foi mais acentuada em folhas e raízes, com redução de até $75 \%$ da massa fresca de folhas na cultivar M-82 (Figura 1A). A redução da massa foliar, tanto fresca como seca, está correlacionada ( $r=0,99^{*}$ e $0,97^{*}$, respectivamente, Tabela 1) com a redução do número de folhas por planta (Figura 
MORALES, R.G.F. et al. Caracterização de tomateiro...

$3 \mathrm{~A})$, que reduziu linearmente com o aumento do déficit hídrico. Plantas mais vigorosas sob condições de déficit hídrico, teoricamente, apresentam mecanismos fisiológicos que permitem o seu desenvolvimento nessas condições. Contudo, a biomassa excessiva requer uma maior quantidade de água no solo devido à maior transpiração total da planta (Bernier et al., 2008). Assim, a aceleração da senescência e da abscisão foliar sob condições de déficit hídrico é um mecanismo que a planta utiliza para redução da área foliar, tendo como resultado direto a redução da transpiração e a conservação da água no solo (Anjum et al., 2011).
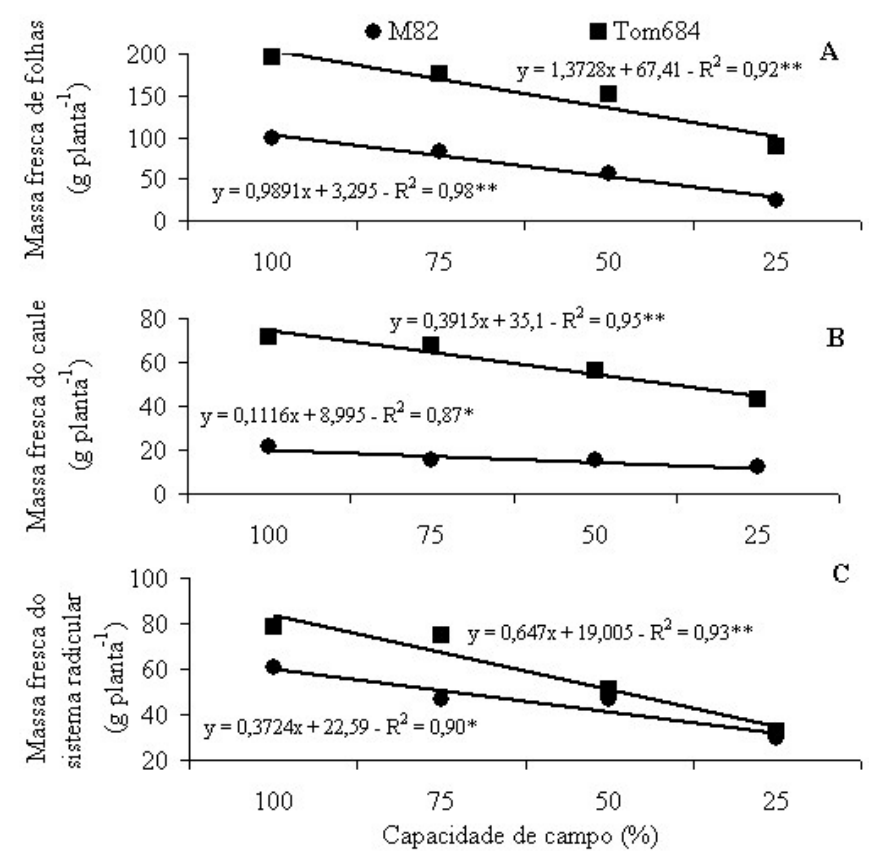

FIGURA 1 - Massa fresca de folhas (A), caule (B) e sistema radicular (C) em diferentes níveis de umidade do solo. ${ }^{*} e^{* *}-5 \%$ e $1 \%$ de probabilidade de erro, respectivamente. ns- não significativo. Lavras, UFLA, 2011.
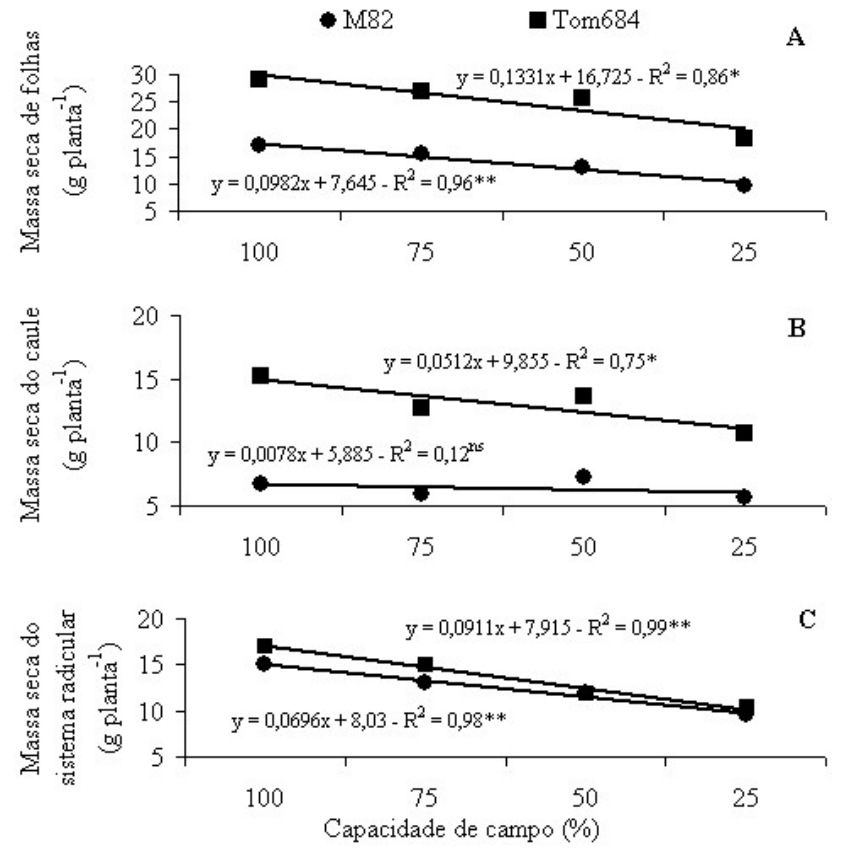

FIGURA 2 - Massa seca de folhas (A), caule (B) e sistema radicular (C) em diferentes níveis de umidade do solo. ${ }^{*} \mathrm{e}^{* *} 5 \%$ e $1 \%$ de probabilidade de erro, respectivamente. Lavras, UFLA, 2011. 
MORALES, R.G.F. et al. Caracterização de tomateiro...

TABELA 1 - Correlação entre as características morfofisiológicas do tomateiro submetido a diferente níveis de umidade do solo

\begin{tabular}{|c|c|c|c|c|c|c|c|c|c|c|}
\hline & $\begin{array}{l}\text { Produção de } \\
\text { frutos } \\
\left(\text { kg.planta }^{-1}\right)\end{array}$ & $\begin{array}{l}\text { Altura das } \\
\text { plantas } \\
(\mathrm{cm})\end{array}$ & $\begin{array}{l}\text { Número de } \\
\text { folhas } \\
\text { por planta } \\
\left(\text { folhas.pla } \text { nta }^{-1} \text { ) }\right.\end{array}$ & $\begin{array}{l}\text { Massa } \\
\text { seca de } \\
\text { folhas } \\
\text { (g.planta }^{-1} \text { ) }\end{array}$ & $\begin{array}{l}\text { Massa } \\
\text { seca do } \\
\text { sistema } \\
\text { radicular } \\
\text { (g.planta }^{-1} \text { ) }\end{array}$ & $\begin{array}{l}\text { Fotossínte- } \\
\text { se } \\
\left(\mu \mathrm{mol} \mathrm{CO}_{2}\right. \\
\left.\mathrm{m}^{-2} \mathrm{~s}^{-1}\right)\end{array}$ & $\begin{array}{l}\text { Condutân- } \\
\text { cia estomá } \\
\text { tica } \\
\left(\mathrm{mol} \mathrm{m}^{-2} \mathrm{~s}^{-}\right. \\
1)\end{array}$ & $\begin{array}{l}\text { Transpira- } \\
\text { ção } \\
\left(\mathrm{mmol} \mathrm{m}^{-2}\right. \\
\left.\mathrm{s}^{-1}\right)\end{array}$ & $\begin{array}{l}\text { Temperatura } \\
\text { Foliar } \\
\left({ }^{\circ} \mathrm{C}\right)\end{array}$ & 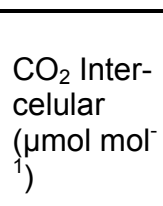 \\
\hline & 1. & 2. & 3. & 4. & 5. & 6. & 7. & 8. & 9. & 10. \\
\hline 1. & & $0,99^{* *}$ & $0,99^{* *}$ & $0,95^{*}$ & $0,99^{* *}$ & $0,99^{*}$ & $0,97^{*}$ & $0,99^{* *}$ & $-0,98^{*}$ & $0,93^{*}$ \\
\hline 2. & & & $0,99^{* *}$ & $0,96^{*}$ & $0,99^{* *}$ & $0,96^{*}$ & $0,98^{*}$ & $0,97^{*}$ & $-0,99^{* *}$ & $0,95^{*}$ \\
\hline 3. & & & & $0,97^{*}$ & $0,99^{* *}$ & $0,96^{*}$ & $0,97^{*}$ & $0,98^{*}$ & $-0,99^{* *}$ & $0,97^{*}$ \\
\hline 4. & & & & & $0,97^{*}$ & $0,92^{*}$ & $0,89^{*}$ & $0,96^{*}$ & $-0,97^{*}$ & $0,99^{* *}$ \\
\hline 5. & & & & & & $0,96^{*}$ & $0,98^{*}$ & $0,97^{*}$ & $-0,99^{* *}$ & $0,96^{*}$ \\
\hline 6. & & & & & & & $0,93^{*}$ & $0,99^{* *}$ & $-0,93^{*}$ & $0,90^{*}$ \\
\hline 7. & & & & & & & & $0,93^{*}$ & $-0,99^{*}$ & $0,88^{*}$ \\
\hline 8. & & & & & & & & & $-0,99^{*}$ & $0,94^{*}$ \\
\hline 9. & & & & & & & & & & $-0,99^{*}$ \\
\hline
\end{tabular}

${ }^{*} \mathrm{e}^{* *}-5 \%$ e $1 \%$ de probabilidade de erro pelo teste $\mathrm{t}(\mathrm{p}<0,05)$, respectivamente. ns- não significativo.
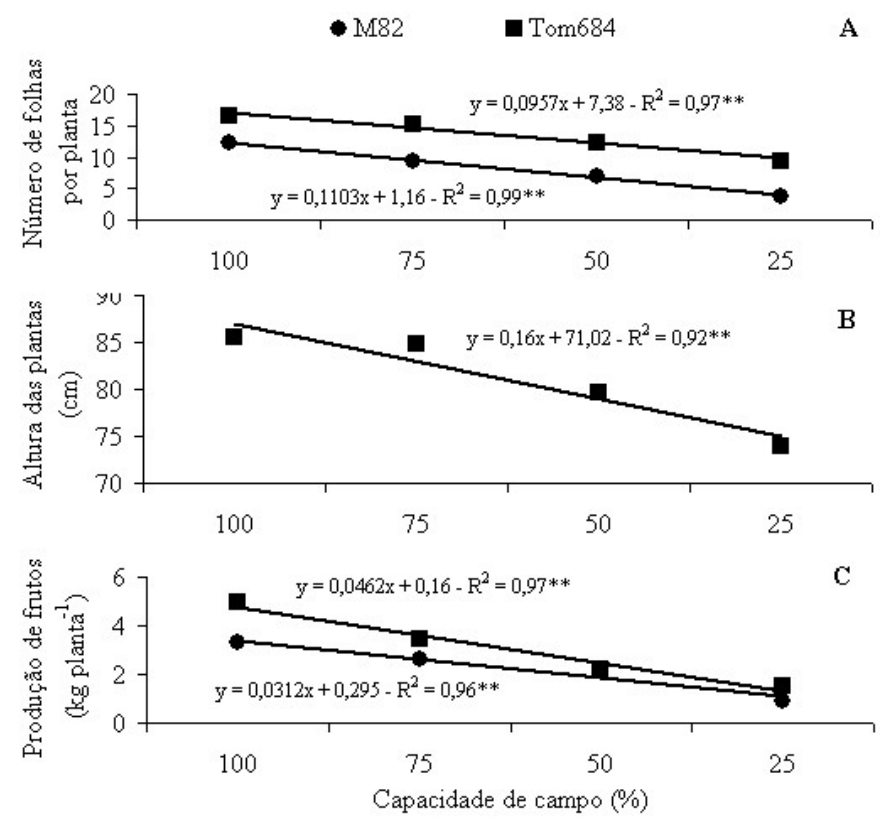

FIGURA 3 - Número de folhas (A), altura das plantas (B) e produção de frutos (C) em diferentes níveis de umidade do solo. ${ }^{*} e^{* *}-5 \%$ e $1 \%$ de probabilidade de erro, respectivamente. Lavras, UFLA, 2011. 
MORALES, R.G.F. et al. Caracterização de tomateiro...

A altura da cultivar TOM684 reduziu linearmente com o aumento do déficit hídrico do solo (Figura 3B), medindo aos 80 DAT, $85,6 \mathrm{~cm}$ quando cultivadas no solo com $100 \%$ capacidade de campo (Cc); e 74,0 cm em $25 \%$ da Cc, redução de $11,6 \mathrm{~cm}$ na altura. Plantas sob déficit hídrico reduzem a turgecência celular (Torrecillas et al., 1996) e a produção de etileno, o que resulta na menor expansão da célula e, consequentemente, na redução do crescimento. Partindo desse pressuposto, plantas que não reduzem a altura sob condições de déficit hídrico, podem apresentar mecanismos morfofisiológicos que permitem o seu desenvolvimento nessas condições, ou seja, possuem mecanismos que aumentam a eficiência no uso da água ou a resistência ao déficit hídrico.

A redução do crescimento vegetativo proporcionado pelo déficit hídrico pode ter influenciado indiretamente a produção de frutos. A cultivar TOM-684 reduziu a produção de frutos de 4,99 para $1,85 \mathrm{~kg}_{\text {planta }}{ }^{-1}$ entre as umidades de 100 e $25 \%$ da $\mathrm{Cc}$, respectivamente. O mesmo foi observado com a cultivar $\mathrm{M}-82$, que reduziu a produção de 3,34 para 0,89 $\mathrm{kg}_{\text {planta }}{ }^{-1}$ (Figura $3 \mathrm{C}$ ). Seleção direta para rendimento em altos níveis de precisão e intensidade de seleção, ao contrário da seleção indireta para características fisiológicas correlacionadas, tem demonstrado ser o mais efetivo arranjo para melhoramento sob ambientes estressantes (Intrigliolo \& Castel, 2006; Bernier et al., 2008). Contudo, os principais trabalhos que levam a essa conclusão foram realizados com cereais, em que a qualidade da colheita é muito menos importante em comparação com o tomateiro. Assim, a seleção de plantas resistentes à seca utilizando com critério a produção de frutos de tomate pode apresentar inconvenientes, pois a seleção pode estar em sentido contrário ao da qualidade do fruto, tornando a planta produtiva em condições de seca e com frutos indesejáveis.

A redução da produção de frutos está correlacionada com a menor taxa fotossintética $(r=$ $0,99^{\star}$ ) observada nos tratamentos com maior déficit hídrico. A fotossíntese reduziu de 8,61 para 4,18 $\mu \mathrm{mol} \mathrm{CO}_{2} \mathrm{~m}^{-2} \mathrm{~s}^{-1}$ entre os tratamentos de 100 e 25 $\%$ da Cc, redução de aproximadamente $50 \%$ (Tabela 2). A redução da fotossíntese está relacionada à redução da absorção de $\mathrm{CO}_{2}$ estimado pelo $\mathrm{CO}_{2}$ intercelular $\left(r=0,90^{*}\right)$, que reduziu de 92,63 para $59,20 \mu \mathrm{mol} \mathrm{mol}^{-1}$ de $\mathrm{CO}_{2}$ entre as umidades do solo de 100 e $25 \%$ da Cc, respectivamente. A razão $\mathrm{Ci} / \mathrm{Ca}$ apresentou resultados semelhantes ao $\mathrm{CO}_{2}$ intercelular, reduzindo seus valores com $\mathrm{O}$ aumento da intensidade do estresse. Segundo Faver et al. (1996) a redução na atividade fotossintética pela menor assimilação do $\mathrm{CO}_{2}$ e a senescência das folhas são indicadores do efeito do déficit hídrico sobre uma cultura. A redução da taxa de assimilação de $\mathrm{CO}_{2}$, durante o déficit hídrico, devese à menor disponibilidade de $\mathrm{CO}_{2}$ no interior da folha, causada pelo fechamento dos estômatos em resposta ao decréscimo na disponibilidade de água no solo (Rosa et al., 1991). Outras mudanças podem ocorrer juntamente com o fechamento dos estômatos, como a alteração na síntese de clorofila, alterações funcionais e estruturais em cloroplastos e distúrbios nos processos de acumulação, transporte e distribuição de assimilados (Anjum et al., 2011).

TABELA 2 - Efeito do déficit hídrico sobre a fotossíntese, $\mathrm{CO}_{2}$ intercelular, transpiração, umidade intercelular e temperatura foliar de linhagens de tomateiro. Lavras, UFLA, 2011.

\begin{tabular}{|c|c|c|c|c|c|c|}
\hline \multirow[b]{2}{*}{ Variáveis } & \multicolumn{4}{|c|}{ Capacidade de campo ( \%) } & \multicolumn{2}{|c|}{$\mathrm{R}^{2}$} \\
\hline & 100 & 75 & 50 & 25 & Linear & Quadr. \\
\hline $\begin{array}{l}\text { Fotossíntese } \\
\left(\mu \mathrm{mol} \mathrm{CO}_{2} \mathrm{~m}^{-2} \mathrm{~s}^{-1}\right) \\
\mathrm{CO}_{2} \text { Intercelular }\end{array}$ & $8,61^{\#}$ & 6,34 & 5,73 & 4,18 & $0,95^{\star \star}$ & $0,96^{\star *}$ \\
\hline$\left(\mu \mathrm{mol} \mathrm{mol}{ }^{-1}\right)$ & 92,63 & 87,84 & 80,35 & 59,20 & $0,88^{*}$ & $0,99^{* *}$ \\
\hline $\begin{array}{l}\text { Razão } \mathrm{Ci} / \mathrm{Ca} \\
\text { Eficiência no uso da áqua }\left(\mathrm{umol} \mathrm{mol}^{-1} \mathrm{CO}_{2} / \mathrm{mmol}\right.\end{array}$ & 0,81 & 0,76 & 0,70 & 0,51 & $0,90^{* *}$ & $0,98^{* *}$ \\
\hline $\begin{array}{l}\left.\mathrm{m}^{-2} \mathrm{~s}^{-1} \mathrm{H}_{2} \mathrm{O}\right) \\
\text { Transpiração }\end{array}$ & 1,38 & 1,21 & 1,17 & 1,05 & $0,85^{*}$ & $0,86^{*}$ \\
\hline$\left(\mathrm{mmol} \mathrm{m} \mathrm{m}^{-2} \mathrm{~s}^{-1}\right)$ & 6,24 & 5,24 & 4,92 & 3,97 & $0,96^{* *}$ & $0,96^{* *}$ \\
\hline $\mathrm{H}_{2} \mathrm{O}$ Intercelular ( \%) & 47,67 & 44,42 & 41,50 & 39,93 & $0,97^{\star *}$ & $0,99^{* *}$ \\
\hline Temperatura Foliar $\left({ }^{\circ} \mathrm{C}\right)$ & 27,82 & 28,27 & 29,33 & 30,35 & $0,97^{* *}$ & $0,99^{* *}$ \\
\hline
\end{tabular}

"Valores médios referentes as duas linhagens. ${ }^{*} \mathrm{e}^{* *}$ - significativos a 5 e $1 \%$ de probabilidade de erro, respectivamente. 
MORALES, R.G.F. et al. Caracterização de tomateiro...

A eficiência no uso da água foi reduzida com a intensificação do déficit hídrico, variando de 1,38 a $1,05 \mu \mathrm{mol} \mathrm{mol}{ }^{-1} \mathrm{CO}_{2} / \mathrm{mmol} \mathrm{m}^{-2} \mathrm{~s}^{-1} \mathrm{H}_{2} \mathrm{O}$ entre os tratamentos de 100 e $25 \%$ da Cc (Tabela 2). Esses resultados divergem de outros autores (Marouelli et al., 2003; Sá et al., 2005), que observaram aumento linear na eficiência no uso da água quando as plantas de tomateiro foram submetidas aos níveis crescentes de tensão de água no solo.

A redução na disponibilidade de água do solo diminuiu a transpiração das plantas de 6,24 para $3,97 \mathrm{mmol} \mathrm{H}_{2} \mathrm{O} \mathrm{m} \mathrm{s}^{-2}$, redução de aproximadamente $40 \%$, proporcional ao observado com a taxa fotossintética $\left(r=0,99^{* *}\right)$. A redução da transpiração foi acompanhada pela redução da quantidade de água intercelular (47,67 \% para 39,93 \%) (Tabela 2). A redução da transpiração, com a manutenção da taxa fotossintética, pode aumentar a eficiência do uso da água pela planta (Condon et al., 2004). Por outro lado, a manutenção da traspiração em condições de déficit hídrico, sem a redução do potencial de água da folha, pode ser um indicativo de que as plantas possuem mecanismos de tolerância ao estressse hídrico. Cultivares de arroz conhecidas pela resistência a seca não estavam associadas com a eficiência no uso da água, mas com a capacidade de manter alta transpiração sob condições de déficit hídrico, devido um sistema radicular profundo e denso (Blum, 2009).

Com a redução da umidade do solo houve aumento da temperatura foliar, variando de 27,82 a $30,35{ }^{\circ} \mathrm{C}$ entre as umidades de 100 e $25 \%$ da Cc (Tabela 2). Esses resultados estão relacionados a menor transpiração das plantas $\left(r=-0,95^{\star}\right)$, pois a tranpiração é o principal mecanismo de arrefecimento dos vegetais. Além do mais, altas temperaturas foliares estão relacionadas com a redução da fixação de carbono nas diversas etapas da fotossíntese (Medlyn et al., 2002). Essa variação na temperatura foliar e do dossel foliar podem ser utilizados para estimar o estresse hídrico das plantas, como observado na cultura do milho (Tilling et al., 2007; Winterhalter et al., 2011). Em estudos sobre indicadores de déficit hídrico, Kirkham (2005) sugeriu aprofundamento nas avaliações de temperatura foliar, com termômetro infravermelho, para obter índices de estresse hídrico. Salientou, também, que tais estudos devem relacionar o potencial da água na folha com medidas tensiométricas, que são mais simples, baratas e mostram consistência de forma geral. Peñuelas et al. (1992) também recomendou o uso da temperatura foliar para manejo de água em morangueiro, pois ela permite verificar diferenças de estado hídrico da cultura em condições de demanda atmosférica amena, como as que ocorrem em estufas plásticas.

A condutância estomática diferiu entre as duas linhagens, com maior condutância para a cultivar TOM-684, que reduziu de 0,70 para 0,25 mol m$~^{-2} \mathrm{~s}^{-1}$ entre as umidades de 100 e $25 \%$ da Cc, redução de aproximadamente $65 \%$ na condutância (Figura 4). A condutância estomática correlacionou linearmente com fotossíntese $\left(r=0,93^{*}\right)$, transpiração $\left(r=0,93^{*}\right)$ e $\mathrm{CO}_{2}$ intercelular $\left(r=0,88^{*}\right)$, mas correlacionou com a produção de frutos $(r=$ $0,97^{\star}$ ) (Tabela 1). Easlon \& Richards (2009) cultivaram cinco espécies de tomateiro sob dois regimes hídricos: com irrigação durante todo o ciclo; e suspensão da irrigação quando a sexta folha verdadeira estava completamente desenvolvida, durante 20 dias, irrigando-se normalmente após esse período. No primeiro caso, a condutância média observada foi exatamente a mesma observada nesse trabalho nas condições de $100 \%$ da Cc $\left(0,56 \mathrm{~mol} \mathrm{~m}^{-2} \mathrm{~s}^{-1}\right)$. Contudo, após o período de 20 dias sob déficit hídrico, a condutância reduziu para $0,14 \mathrm{~mol} \mathrm{~m}^{-2} \mathrm{~s}^{-1}$, valor inferior ao observado nesse experimento para o tratamento com maior déficit hídrico $(25 \%$ da $\mathrm{Cc})$. A redução na condutância se deve ao decréscimo na disponibilidade de água no solo, que ocasiona queda no potencial da água nas folhas, levando-as à perda de turgescência e à redução da condutância estomática (Paiva et al., 2005). Outra explicação é a sinalização proporcionada pelo ácido abscísico produzido no sistema radicular, induzindo o fechamento dos estômatos presentes nas folhas (Taylor et al., 2000), reduzindo assim a condutância estomática.

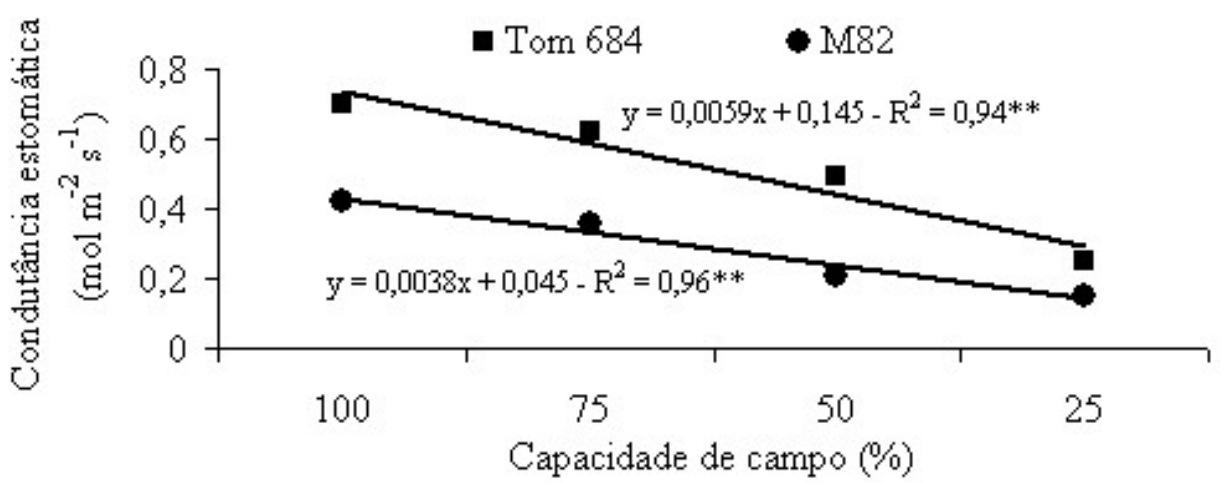

FIGURA 4 - Condutância estomática nas linhagens de tomateiro TOM-684 e M-82 em diferentes níveis de umidade do solo. ${ }^{*} e^{* *}-5 \%$ e $1 \%$ de probabilidade de erro, respectivamente. Lavras, UFLA, 2011. 
MORALES, R.G.F. et al. Caracterização de tomateiro...

As linhagens TOM-684 e M-82 diferiram em quase todos os caracteres morfológicos avaliados, com exceção da massa seca de raízes (Tabela 3 ). Essas diferenças morfológicas estão relacionadas ao modo de crescimento das plantas, determinado e indeterminado, que naturalmente diferem na maior parte dos caracteres avaliados. Quanto as características fisiológicas, a única diferença observada entre as linhagens foi na condutância estomática.

TABELA 3 - características morfofisiológicas das linhagens de tomateiro m-82 e tom-684 submetidas aos

\begin{tabular}{|c|c|c|c|c|}
\hline \multirow{3}{*}{$\begin{array}{l}\qquad \begin{array}{c}\text { Características } \\
\text { morfológicas e fisiológicas }\end{array} \\
\text { Produção de frutos }\left(\text { kg.planta }{ }^{-1}\right)\end{array}$} & \multicolumn{4}{|c|}{ Linhagens } \\
\hline & \multirow{2}{*}{$\frac{M-82}{2,24}$} & \multicolumn{3}{|c|}{ TOM-684 } \\
\hline & & $\mathrm{b}$ & 3,05 & a \\
\hline Número de folhas por planta & 8,05 & $\mathrm{~b}$ & 13,36 & a \\
\hline Massa fresca de folhas (g.planta ${ }^{-1}$ ) & 65,11 & $\mathrm{~b}$ & 153,21 & a \\
\hline Massa fresca de raízes (g.planta ${ }^{-1}$ ) & 45,87 & $\mathrm{~b}$ & 59,44 & a \\
\hline Massa fresca do caule (g.planta ${ }^{-1}$ ) & 15,97 & $\mathrm{~b}$ & 59,57 & a \\
\hline Massa seca de folhas (g.planta ${ }^{-1}$ ) & 13,78 & $\mathrm{~b}$ & 25,04 & a \\
\hline Massa seca de raízes (g.planta ${ }^{-1}$ ) & 11,95 & a & 14,52 & a \\
\hline Massa seca do caule (g.planta ${ }^{-1}$ ) & 6,37 & $\mathrm{~b}$ & 13,05 & a \\
\hline Fotossíntese $\left(\mu \mathrm{mol} \mathrm{CO} \mathrm{Cm}^{-2} \mathrm{~s}^{-1}\right)$ & 5,94 & a & 6,50 & a \\
\hline Condutância Estomática $\left(\mathrm{mol} \mathrm{m} \mathrm{m}^{-2} \mathrm{~s}^{-1}\right)$ & 0,47 & $\mathrm{~b}$ & 0,80 & a \\
\hline Transpiração $\left(\mathrm{mmol} \mathrm{m} \mathrm{m}^{-2} \mathrm{~s}^{-1}\right)$ & 5,20 & a & 4,98 & a \\
\hline Temperatura Foliar $\left({ }^{\circ} \mathrm{C}\right)$ & 28,61 & a & 29,27 & a \\
\hline $\mathrm{H}_{2} \mathrm{O}$ Intercelular ( \%) & 44,54 & a & 42,22 & a \\
\hline $\mathrm{CO}_{2}$ Intercelular $\left(\mu \mathrm{mol} \mathrm{mol}{ }^{-1}\right)$ & 87,40 & a & 72,60 & a \\
\hline Eficiência no uso da água $\left(\mu \mathrm{mol} \mathrm{mol}{ }^{-1} \mathrm{CO}_{2} / \mathrm{mmol} \mathrm{m}^{-2} \mathrm{~s}^{-1} \mathrm{H}_{2} \mathrm{O}\right)$ & 1,29 & a & 1,12 & a \\
\hline
\end{tabular}

Médias seguidas pela mesma letra minúscula na linha não diferem entre si pelo teste de Tukey $(p<0,05)$.

A utilização de caracteres morfológicos aliados ao rendimento de frutos pode fornecer os subsídios necessários para identificação de plantas com maior resistência ao déficit hídrico. Como a determinação do número de folhas e da altura das plantas são caracteres fáceis de serem avaliados, a sua utilização em programas de melhoramento poderá ser útil como ferramenta para seleção de plantas com maior resistência ao déficit hídrico. Dentre os caracteres fisiológicos, a fotossíntese, a transpiração, a condutância estomática e a temperatura foliar podem auxiliar na seleção de plantas resistentes ao déficit hídrico.

\section{CONCLUSÃO}

Plantas de tomateiro submetidas ao déficit hídríco reduzem a produção de frutos, a altura das plantas, o número de folhas, a taxa fotossintética, a transpiração, a condutância estomática e aumentam a temperatura foliar.
A altura de plantas e o número de folhas são os melhores caracteres para a seleção indireta de plantas de tomateiro resistentes ao déficit hídrico.

\section{AGRADECIMENTOS}

Ao "Conselho Nacional de Desenvolvimento Científico e Tecnológico" (CNPq) e "Coordenação de Aperfeiçoamento de Pessoal de Nível Superior" (CAPES), pelo suporte financeiro para a execução do projeto. 
MORALES, R.G.F. et al. Caracterização de tomateiro...

\section{REFERÊNCIAS}

1. ANJUM, S. A. et al. Morphological, physiological and biochemical responses of plants to drought stress. African Journal of Agricultural Research, Lesotho, v. 6, n. 9, p. 2026-2032, 2011

2. BERGONCI, J. I. et al. Potencial da água na folha como um indicador de déficit hídrico em milho. Pesquisa Agropecuária Brasileira, Brasília, v. 35, n. 8, p. 1531-1540, 2000.

3. BERNIER, J. et al. Breeding upland rice for drought resistance. Journal of the Science of Food and Agriculture, Oxford, v. 88, n. 6, p. 927-939, 2008.

4. BLUM, A. Effective use of water (EUW) and not water-use efficiency (WUE) is the target of crop yield improvement under drought stress. Field Crops Research, Amsterdam, v. 112, n. 1, p. 119-123, 2009

5. BOHNERT, H. J.; JENSEN, R. G. Strategies for engineering water-stress tolerance in plants. Trends in Biotechnology, Oxford, v. 14, n. 1, p. 89-97, 1996.

6. BORTOLINI, F. et al. Características morfofisiológicas associadas à tolerância à seca em sete genótipos da coleção nuclear de trevo branco. Ciência Rural, Santa Maria, v. 41, n. 9, p. 1632-1638, 2011.

7. CONDON, A. G. et al. Breeding for high water-use efficiency. Journal of Experimental Botany Oxford, v. 55, n. 407, p. 2447-2460, 2004.

8. EASLON, H. M.; RICHARDS, J. H. Drought response in self-compatible species of tomato (Solanaceae). American Journal of Botany, Saint Louis, v. 96, n. 3, p. 605-611, 2009.

9. FAVER, K. L. et al. Late season water stress in cotton: Leaf gas exchange and assimilation capacity. Crop Science, Madison, v. 36, n. 1, p. 922-928, 1996

10. HETHERINGTON, A. M.; WOODWARD, F. I. The role of stomata in sensing and driving environmental change. Nature, New York, v. 424, n. 24, p. 901-908, 2003.

11. INTRIGLIOLO, D. S.; CASTEL, J. R. Performance of various water stress indicators for prediction of fruit size response to deficit irrigation in plum. Agricultural Water Management, Amsterdam, v. 83, n. 1, p. 173-180, 2006.

12. KATERJI, N. et al. Etude de quelques critères indicateurs de l'état hydrique d'une culture de tomate en région semiaride. Agronomie, Lisbonne, v. 8, n. 5, p. 425-433, 1988.

13. KERSTIENS, G. Water transport in plant cuticles: an update. Journal of Experimental Botany, Oxford, v. 57, n. 11, p. 2493-2499, 2006.

14. KIRKHAM, M. B. Measurement of Canopy Temperature with Infrared Thermometers. In: KIRKHAM, M. B. (Ed.). Principles of Soil and Plant Water Relations. Burlington: Academic Press. 2005. p. 425-435.

15. KOCHLER, M. et al. Modelling the effects of soil water limitations on transpiration and stomatal regulation of cauliflower. European Journal of Agronomy, Amsterdam, v. 26, n. 1, p. 375-383, 2007.

16. LAFITTE, R. Relationship between leaf relative water content during reproductive stage water deficit and grain formation in rice. Field Crops Research, Amsterdam, v. 76, n. 1, p. 165-174, 2002

17. LUO, L. J. Breeding for water-saving and drought-resistance rice (WDR) in China. Journal of Experimental Botany Oxford, v. 61, n. 13, p. 3509-3517, 2010

18. MAROUELLI, W. A. et al. Resposta do tomateiro para processamento a tensões de água no solo, sob irrigação por gotejamento. Engenharia Agrícola, Jaboticabal, v. 23, n. 1, p. 1-8, 2003.

19. MEDLYN, B. E. et al. Temperature responses of parameters of a biochemically based model of photosynthesis. I. Seasonal changes in mature maritime pine (Pinus pinaster Ait.). Plant Cell and Environment, Oxford, v. 25, n. 9, p. 1155-1165, 2002.

20. PAIVA, A. S. et al. Condutância estomática em folhas de feijoeiro submetido a diferentes regimes de irrigação. Engenharia Agrícola, Jaboticabal, v. 25, n. 1, p. 161-169, 2005.

21. PEÑUELAS, J. et al. Remotely measured canopy temperature of greenhouse strawberries as indicator of water status and yield under mild and very mild water stress conditions. Agricultural and Forest Meteorology, Amsterdam, v. 58, $\mathrm{n}$. 1, p. 63-77, 1992.

22. ROSA, L. M. et al. Responses of soybean leaf angle, photosynthesis and stomatal conductance to leaf and soil water potential. Annals of Botany, London, v. 67, n. 1, p. 51-58, 1991.

23. ROYER, D. L. Stomatal density and stomatal index as indicators of paleoatmospheric CO2 concentration. Review of Palaeobotany and Palynology, Amsterdam, v. 114, n. 2, p. 1-28, 2001.

24. SÁ, N. S. A. et al. Behavior of tomato crop under different soil water tensions in a greenhouse. Revista Brasileira de Engenharia Agrícola e Ambiental, Campina Grande, v. 9, n. 3, p. 341-347, 2005.

25. SRINIVASA RAO, N. K. et al. Tolerance to Water Stress in Tomato Cultivars. Photosynthetica, Prague, v. 38, n. 3, p. 465-467, 2001.

26. TAYLOR, I. B. et al. Control of abscisic acid synthesis. Journal of Experimental Botany Oxford, v. 51, n. 350, p. 15631574,2000

27. TILLING, A. K. et al. Remote sensing of nitrogen and water stress in wheat. Field Crop Research, Amsterdam, v. 104, n. 1, p. 77-85, 2007

28. TORRECILLAS, A. et al. Strategies for drought resistance in leaves of two almond cultivars. Plant Science, London, v. 118, n. 2, p. 135-143, 1996.

29. WINTERHALTER, L. et al. High throughput phenotyping of canopy water mass and canopy temperature in wellwatered and drought stressed tropical maize hybrids in the vegetative stage. European Journal of Agronomy, Amsterdam, v. 35, n. 1, p. 22-32, 2011. 